\title{
The Impact of Broadband Diffusion in Assessing Innovation at the Institutions of Higher Learning in Kenya
}

\author{
Article by Rajab Philip Muchiri \\ Computer Science, Texila American University, Kenya \\ E-mail: philipmuchiri2014@gmail.com
}

\begin{abstract}
Objective: The aim of the research was to study the impact of broadband diffusion in assessing innovation in institutions of higher learning in Kenya.

Background: The Government of Kenya realized the importance of broadband provision to stimulate economic development through innovation and established the Kenya Education Network Trust (KENET) - a national research and education network that promotes the use of broadband in teaching, learning and research in institutions of higher learning in Kenya. The aim of KENET was to interconnect all the universities in Kenya by setting up a cost effective and sustainable private network with high speed access to the global internet.

Methodology: This study applied descriptive survey research design and a logistic regression model was used as an inferential analysis tool in the quantitative analysis. Inferential statistics used to analyse the model were; overall model evaluation, goodness-of-fit statistics, and statistical tests of individual predictors and validations of predicted probabilities.

Results: Reliability measures were above the recommended level of 0.70 as an indicator for adequate internal consistency. Inferential statistics used to analyse the model showed that the model performed well and was appropriate for the study.

Conclusion: Broadband diffusion in institutions of higher learning in Kenya is inhibited by poor infrastructural development attributed to high costs of connections and bandwidth acquisition and a high demand for broadband among the students and staff. Policies in broadband regulation from the national government and institutional governance are prudent in controlling and enabling access to this important resource for innovative purpose.
\end{abstract}

Keywords: Broadband diffusion, Innovation, Education, Internet, Bandwidth, Regression Model.

\section{Introduction}

The Government of Kenya has over the years improved the regulatory environment to promote growth of the ICT sector and increase availability of broadband Internet in the country. The Kenya Education Network Trust (KENET) was established by the government of Kenya to promote the use of ICT in Teaching, Learning and Research in Higher Education Institutions in Kenya. The main aim of KENET was to interconnect all the universities, tertiary and research Institutions in Kenya by setting up a cost effective and sustainable private network with high speed access to the global Internet. This network trust currently provides broadband to over 90 member institutions including universities both private and public in Kenya.

In their E-Readiness Survey of Kenyan Universities (2013) Report, Kashorda and Waema (2014) observed that the networked PCs available per 100 students ratio was 3.8 in Kenyan universities, which was considered quite low. The e-readiness survey also indicated that 16,174 student lab computers were available for 423,664 students at the 30 universities and only $17 \%$ of students accessed computers from their campuses. On the other hand, 53\% of students owned over 200,000 laptop computers in the 30 universities. The report therefore recommended that universities invest in student computer labs in order to serve all students who do not have laptop computers or those who may not wish to carry their laptop computers to the campus in the university. It was further revealed by the e-readiness survey that universities in 2013 achieved broadband internet of $4.0 \mathrm{Mb} / \mathrm{s}$ per 1,000 students compared to only $0.431 \mathrm{Mb} / \mathrm{s}$ per 1,000 students in 2008 . 
DOI: $10.21522 / \mathrm{TIJAR} .2014 .04 .02 . A r t 021$

ISSN: $2520-3088$

Even if all universities are inter-connected to the national fiber backbone network, they should invest sufficiently in their internal campus backbone and wireless network infrastructure that will make it easier for students to use their own laptops and smart phones on campus to access learning materials and other student services. Besides the low PC ratio, the students considered the campus networks slow and unstable (Kashorda and Waema, 2014). The current study uses KENET as a case study to assess the effectiveness of broadband collaborations in IHL for innovative projects.

Broadband communications is the foundation of developing a robust society that is informative and innovative. Widespread broadband diffusion encourages innovation, contributing to production and growth and attracts foreign investment (ITU, 2003). The International Telecommunication Union (ITU) defines broadband as a network offering a combined speed equivalent to 256 kilobytes per second (kbit/s) or greater in one or both upstream and downstream directions (ITU, 2006). In terms of the broadband penetration rate, by July 2015, there were over 36.113 million mobile subscribers and mobile penetration of 80.68 per 100 inhabitants in Kenya (ITU, 2016). Fixed broadband is the transmission capacity with sufficient bandwidth to permit combined provision of voice, video and data through a fixed line such as Digital Subscriber Line (DSL) and cable modem (ITU, 2006). Meanwhile, mobile broadband systems support data transport rates of at least $256 \mathrm{kbit} / \mathrm{s}$ for all radio environments, which exceed the rates under second generation wireless networks These mobile broadband systems enable many advanced video applications such as mobile videoconferencing, video phone or mail, mobile TV or video player and digital audio or video delivery (ITU, 2003). Although there is an overall rapid growth in broadband diffusion, still many countries are in the early stages of broadband deployment and are assessing policy strategies to promote faster broadband adoption. Local loop unbundling (LLU) and facilities-based competition has been found out to be an important policy initiative to promote rapid fixed broadband diffusion in a number of countries around the world. Local loop unbundling refers to the process of requiring incumbent operators to open as a whole or in part, the last mile of their telecommunications networks to competitors (ITU, 2003). Platform competition (facilities-based competition among several different broadband platforms) is crucial for reducing prices, increasing the number of customers, improving the quality of service and promoting investment and innovation (ITU, 2003). Experts differ on whether single or multiple standards promote faster diffusion of mobile communications.

There were over 555 million fixed broadband subscribers and 940 million mobile broadband subscribers at the end of 2010 (ITU, 2010). This demonstrates a steady growth of broadband adoption throughout the world. The dominant fixed broadband access platforms in OECD countries are DSL with $58 \%$ of the fixed broadband market and cable modem (29\%) (OECD, 2010). In the mobile broadband markets, standard mobile (with $73 \%$ of the mobile broadband markets) is a dominant access platform (OECD, 2010). Until June 2010, Netherlands, Denmark, South Korea, and Switzerland had the highest fixed broadband penetration rates among OECD countries (OECD, 2010). The extent of mobile broadband diffusion varies widely across countries and regions. In 2010, South Korea, Japan, Sweden and Norway were leading mobile broadband economies in terms of the mobile broadband penetration rate (OECD, 2010). CDMA 2000 and WCDMA are the two main standards for $3 \mathrm{G}$ wireless technologies. Most of the European Community countries adopted WCDMA for 3G wireless services (ITU, 2006) while many countries in the Americas, Africa and Asia adopted CDMA 2000 or both CDMA 2000 and WCDMA in their 3G markets (ITU, 2006).

There is a growing body of empirical research on fixed broadband diffusion. In some empirical studies, it was found out that inter-modal competition, LLU, and demographic variables such as income and population density increase fixed broadband diffusion (Grosso et al., 2006). Analysis of data from 14 European countries, Distaso et al. (2006) argued that inter-platform competition drives broadband diffusion while competition in the DSL market does not play a significant role. Some previous empirical studies on initial fixed broadband diffusion in the United States found inter-modal competition as a driver of fixed broadband diffusion in the United States (Denni and Gruber, 2005). Studies of 30 OECD countries by Cava-Ferreruela and Alabau-Muňoz (2006) found that technological competition, lower deployment costs of infrastructure and predilection to use new technologies are key factors for broadband demand and supply. By employing logit regression 
analysis, Garcia-Murillo (2005) found out that unbundling an incumbent's infrastructure only results in a substantial increase in broadband deployment for middle-income countries but not for their high income counterparts as a whole. Kim et al. (2003) suggests that the attitude toward information and technology and the cost conditions of deploying advanced networks are the most consistent factors explaining broadband uptake in OECD countries. It is confirmed that broadband infrastructure is increasingly recognized as fundamental for economic growth in many countries (OECD, 2010). Some empirical studies measured the economic impacts of the broadband infrastructure on growth (Lehr et al., 2006; Koutroumpis, 2009). Koutroumpis (2009) estimated the economic impact of broadband infrastructure on growth in OECD countries and found out that there are increasing returns to broadband telecommunications investments, which are consistent with the persistence of network effects. His study indicated there is evidence of a critical mass phenomenon in broadband infrastructure investments. While employing multivariate regression modelling, Lehr et al. (2006) as well found broadband diffusion enhances economic growth and performance, and that the economic impact of broadband is measurable.

Previous empirical studies on global mobile diffusion found that standardization policies, competition and low user cost are influential factors of global mobile diffusion (Rouvinen et al., 2006). In the economics of standards, studies have focused on the private and social incentives for standardization (Gandal, 2002). Even though market-mediated standards may lead to limited network externalities and economies of scale, multiple wireless standards and different types of services across technologies enable the existence of diverse competing systems that may lead to more and better mobile services (Gruber and Verboven, 2001). Early diffusion of digital technologies in mobile markets was faster in Europe-where most countries had adopted a single standard (Gruber and Verboven (2001). In their study, Koski and Kretschmer (2005) concluded that standardization has a positive but insignificant effect on the timing of initial entry of $2 \mathrm{G}$ services but can also lead to higher prices by dampening competition. The effectiveness of public policy in the context of competing standards with network externalities was examined by Cabral and Kretschmer (2007) who concluded that current mobile diffusion levels are quite similar between the United States (multiple standards) and Europe (mostly single standard). Rouvinen (2006) found that standards competition hinders while market competition promotes diffusion in both developed and developing countries. Even with a growing body of literature that addresses the factors contributing to fixed broadband diffusion, the results of empirical studies have not always been consistent while insufficient data has prevented previous studies from capturing the nonlinear nature of broadband diffusion. The results concerning the effects of broadband price, income and competition on broadband diffusion are mixed (OECD, 2010). Although there has been rapid diffusion of mobile broadband technology, only a few empirical studies have focused on the factors that affect mobile broadband diffusion globally. There is also no evidence of any study on fixed and mobile broadband diffusion examining whether mobile broadband is a complement or a substitute for fixed broadband. If mobile broadband is a complement, then it may offer the potential to increase aggregate broadband penetration. If mobile broadband is a substitute then its impact on aggregate broadband penetration is ambiguous. The effect is that it may help accelerate penetration through platform competition, and could also undermine investment in sunk and fixed-line broadband.

\section{Methods}

\section{Empirical model}

The study used a logistic regression model as an inferential analysis tool in the quantitative aspects of the research. In the research, IHL were viewed as adopters of broadband innovations. Once broadband innovations were adopted, consumers of broadband innovations (i.e., students, academic staff and administrative staff) intend to be satisfied by the systems adopted and implemented. This assumption is guided by utility maximization theory, and taking the rational choice theory, universities would expect to realize most of the outputs envisaged in each adoption. Consumers therefore, would get satisfaction if the innovations were effectively implemented $\mathrm{U}\left(a_{i}\right)$. If there was failure in effective implementation then utility would be $\mathrm{U}\left(a_{j}\right)$.

The utility maximization model therefore would be: 
DOI: 10.21522/TIJAR.2014.04.02.Art021

ISSN: $2520-3088$

$\mathrm{U}\left(a_{i}\right)>\mathrm{U}\left(a_{j}\right)$

Where $\mathrm{U}\left(a_{i}\right)$ and $\mathrm{U}\left(a_{j}\right)$ denote the utility derived from the innovations' effective implementation $\mathrm{U}\left(a_{i}\right)$ and failure ineffective implementation $\mathrm{U}\left(a_{j}\right)$. The output of this utility model is a binary output (effective implementation(1) and ineffective implementation(0)).The dependent variable took binary response outcomes. Assuming Y to represent successful innovation implementation, then:

$y_{i}=\left[\begin{array}{l}1 \text { if an innovation was effectively implemented }- \text { probability } p \\ 0 \text { if innovation implementation was not effective }- \text { probsbility } 1-p\end{array}\right.$

These values of 1 and 0 are chosen based on the binary outcome of:

$P_{i} \equiv \operatorname{Pr}\left[y_{i}=1 \mid X\right]=F\left(x_{i}^{\prime} \beta\right)$

Where $F($.) is a specific function. In order to ensure that $0 \leq p \leq 1$, then it is natural to specify $F($.) to be a cumulative distribution function. The estimation model selected as appropriate for this research study was the logit model. According to (Peng, Lee, \& Ingersoll, 2002), Logit models are models that can be used to analyze and predict data whose outcome is categorical. Logistic regression analysis is thus suitable where there is a dichotomous outcome - of success or failure. Furthermore, a logit model is well suited for describing and testing relationships of categorical outcomes and one or more categorical or continuous predictors where errors are neither normally distributed nor constant across the entire data range.

Logistic regression is based on the logit concept, which is a natural logarithm of odds ratio. Peng et al. (2002) defined the logistic model as shown below:

$\log (\mathrm{Y})=\ln ($ odds $)-\frac{\ln (\pi)}{1-\pi}=\alpha+\beta X+\varepsilon$

Where

$\alpha$ is $\mathrm{Y}$ intercept.

$\beta$ is a vector of the regression coefficient.

$\pi$ is the probability of the outcome of interest i.e., innovation effectiveness.

$\mathrm{e}=2.71828$ which is the base of natural log.

Taking the inverse therefore:

$\pi_{i}=\operatorname{Pr}\left(Y_{i}=\right.$ outcome of innovation $\left.\mid X_{i}=x_{i}\right)=\frac{\exp \left(\beta 0+\beta 1 x_{i}\right)}{1+\exp \left(\beta 0+\beta 1 x_{i}\right)}$

Where

$\mathrm{X}$ is a vector of categorical or continuous variables.

$\mathrm{Y}$ is always a categorical (dichotomous) variable.

The value of $\beta$ determines the relationship between $X$ and $Y$. If $\beta>0$, larger or smaller values of $X$ are associated with larger or smaller values of the logit of $\mathrm{Y}$. The converse also applies: if $\beta<0$, larger or smaller values of $X$ are associated with larger or smaller value of the logit of $Y$. And where $\beta$ $=0$ there is no linear relationship.

For a multiple predictor mode (Peng et al., 2002):

$$
\operatorname{logit}(Y)=\frac{\ln (\pi)}{1-\pi}=\alpha+\beta_{1} X_{1}+\ldots \ldots+\beta_{n} X_{n}
$$

Therefore

$$
\pi=\operatorname{Pr}\left(Y=\text { outcome } \mid X_{1}=X_{2}=X_{3}\right)=\frac{\exp \left(\alpha+\beta_{1} x_{1}+\cdots+\beta_{n} x_{n}\right)}{1+\exp \left(\beta_{1} x_{1}+\cdots+\beta_{n} x_{n}\right)}
$$

Where

$\pi=$ probability of an outcome of technological innovation implementation. $\alpha=\mathrm{Y}$ intercept term.

$\beta=$ regression coefficients.

$\mathrm{Xs}=$ set of predictors.

$\alpha$ and $\beta$ were estimated using the Markov chain Monte Carlo (MC) method for maximum likelihood. Interpretation of results was done using odds ratio for both categorical and continuous 
predictors. Broadband predictors were in the covariates section as independent variables while Innovation( $(\mathrm{Y})$ was the dependent variable. The relationship between the likelihood of a broadband innovation's effective implementation (Y) and its determinants $(\mathrm{X} 1 \ldots . \mathrm{X} 6)$ is described using the following equation:

$Y=\alpha+\beta_{1} X_{1}+\ldots . .+\beta_{5} X_{6}+\varepsilon_{i}$

The logistic regression model is given as follows:

$\ln \left(\frac{P}{1-P}\right)=\alpha+\beta_{1} X_{1}+\ldots+\beta_{5} X_{6}+\varepsilon_{i}$

Where

P: Probability that a broadband innovation was effectively implemented;

1-P: Probability that a broadband innovation was not effectively implemented;

ln: Natural logarithms;

$\alpha$ : Constant of the equation;

$\beta_{1} \ldots \beta_{6}$ : The parameters to be estimated

$X_{1} \ldots X_{6}$ : The explanatory variables;

$X_{1}:$ BBdiffusion1

$X_{2}:$ BBdiffusion2

$X_{3}$ : BBdiffusion3

$X_{4}$ : BBdiffusion4

$X_{5}$ : BBdiffusion5

$X_{6}$ : BBdiffusion6

and

$\varepsilon_{i}$ : the error term.

\section{Measurement development}

The items used for measurement in this research were either developed based on the literature review, adapted from previously validated measures or derived through consultation with ICT experts to ensure that they are valid and reliable. A five-point Likert scale arranged in order of magnitude was employed to assess responses. A representative sample was randomly chosen and used to conduct a pilot test of the measures. Partial least-squares (PLS) analysis technique was applied to test the measurement model to determine the internal consistency reliability and construct validity of the study variables. The technique was also used to test strength and direction of the relationships between variables used in the model (Lohmoller, 1989 and Fronell, 1982). There are only 39 universities in Kenya which represents a small sample population. Therefore PLS was preferred for the research. PLS is applicable for testing and estimating small sample sizes as it converges quickly even for large models with many variables and constructs (Lohmoller, 1989).

Table 1. Summary of measurement scales

\begin{tabular}{|l|l|l|}
\hline Variable construct & Measurement \\
\cline { 2 - 3 } & Code & Measure \\
\hline Broadband diffusion & BBdiffusion1 & $\begin{array}{l}\text { Internet connection speed in my institution is } \\
\text { very good }\end{array}$ \\
\cline { 2 - 3 } & BBdiffusion2 & There are many internet users in my institution \\
\cline { 2 - 3 } & BBdiffusion3 & The high cost of bandwidth limits its usability \\
\cline { 2 - 3 } & BBdiffusion4 & $\begin{array}{l}\text { Amount of bandwidth available in my } \\
\text { institution is adequate }\end{array}$ \\
\cline { 2 - 3 } & BBdiffusion5 & $\begin{array}{l}\text { I can access the internet from within my } \\
\text { institution }\end{array}$ \\
\cline { 2 - 3 } & BBdiffusion6 & $\begin{array}{l}\text { I can use broadband comfortably to perform } \\
\text { my academic work }\end{array}$ \\
\hline
\end{tabular}


DOI: 10.21522/TIJAR.2014.04.02.Art021

ISSN: $2520-3088$

\section{Validation of the measurement scale}

In order to assess the reliability and validity of the measures before using them in the research model, the study applied a two-step approach as suggested by Anderson and Gerbing (1988). Analysis of the measurement model was conducted first before testing the structural relationships between latent constructs.

Composite Reliability $=\sum_{\mathrm{i}=1}^{\mathrm{n}} \mathrm{x}_{\mathrm{i}}{ }^{2} /\left(\sum_{\mathrm{i}=1}^{\mathrm{n}} \mathrm{x}_{\mathrm{i}}{ }^{2}+\left(\sum_{\mathrm{i}=1}^{\mathrm{n}} \mathrm{y}_{\mathrm{i}}\right)\right)$

Average Variance Extracted $=\left(\sum_{\mathrm{i}=1}^{\mathrm{n}} \mathrm{x}_{\mathrm{i}}^{2}\right) / \mathrm{n}$

Where $\mathrm{x}$ is the factor loading, $\mathrm{y}$ is error variance and $\mathrm{n}$ is the number of indicators in each variable construct

Table 2. Reliability measures

\begin{tabular}{|l|l|l|l|l|l|l|}
\hline Construct & $\begin{array}{l}\text { Measurement } \\
\text { Code }\end{array}$ & Loading & t-value & $\begin{array}{l}\text { Composite } \\
\text { reliability }\end{array}$ & $\begin{array}{l}\text { Cronbach's } \\
\text { alpha }(\alpha)\end{array}$ & $\begin{array}{l}\text { Average } \\
\text { Variance } \\
\text { (AVE) }\end{array}$ \\
\hline \multirow{4}{*}{$\begin{array}{l}\text { 4. Broadband } \\
\text { Diffusion } \\
\text { (BBdiffusion) }\end{array}$} & BBdiffusion1 & .751 & 27.035 & 0.883 & 0.741 & 0.548 \\
\cline { 2 - 7 } & BBdiffusion2 & .767 & 22.421 & & & \\
\cline { 2 - 7 } & BBdiffusion3 & .652 & 21.055 & & & \\
\cline { 2 - 7 } & BBdiffusion4 & .735 & 31.202 & & & \\
\cline { 2 - 7 } & BBdiffusion5 & .768 & 38.935 & & & \\
\cline { 2 - 8 } & BBdiffusion6 & .765 & 31.622 & & & \\
\hline
\end{tabular}

Table 2 shows reliability measures above the recommended level of 0.70 as an indicator for adequate internal consistency (Hair, Anderson, Tatham and Black, 1995). Convergent validity is adequate when constructs have an average variance extracted (AVE) of at least 0.5 (Fronell, 1982) or when items loading on their associated factors are above 0.5(Hair, Anderson, Tatham and Black, 1995). Furthermore AVE from the construct should be greater than the variance shared between a particular construct and other constructs in the model (Chin, 1998). Therefore, the constructs used in this study illustrated satisfactory convergent and discriminate validity.

\section{Results}

\section{Broadband diffusion in assessing technological innovation}

To study the role of broadband diffusion in assessing technological innovation, a logistic model was constructed using BBdiffusion variable. The variable constructs used were BBdiffusion1, BBdiffusion2, BBdiffusion3, BBdiffusion4, BBdiffusion5 and BBdiffusion6 as the independent variables while Innovative was used as the dependent variable on the other hand. Below is a table that represents the correlation matrix obtained. This correlation matrix shows all values different from 0 indicating that there was a correlation between the dependent variable and each of the explanatory variables. The relationships between variables in the correlation matrix were significant at $5 \%$ level and the results also showed that there existed a weak association between the independent variables themselves. In addition there was no evidence of multicollinearity. This meant all the variables were acceptable in predicting the dependent variable, Innovative. 
Table 3. Correlation Matrix

\begin{tabular}{lccccccc}
\hline & Const & BB1 & BB2 & BB3 & BB4 & BB5 & BB6 \\
\hline Const & 1.000 & -.027 & -.103 & .216 & .138 & -.488 & -.395 \\
BB1 & -.027 & 1.000 & -.295 & -.097 & .174 & -.561 & .050 \\
BB2 & -.103 & -.295 & 1.000 & -.395 & .178 & .166 & -.550 \\
BB3 & .216 & -.097 & -.395 & 1.000 & .202 & -.178 & -.083 \\
& & & & & & & \\
BB4 & -.138 & .174 & .178 & -.202 & 1.00 & -.466 & -.321 \\
BB5 & -.488 & -.561 & .166 & -.178 & .466 & 1.000 & .168 \\
BB6 & -.395 & .050 & -.550 & -.083 & .321 & .168 & 1.000 \\
\hline
\end{tabular}

Keys

Const - Constant, BB1 - BBdiffusion1, BB2- BBdiffusion2, BB3 -BBdiffusion3, BB4 BBdiffusion4, BB5 -BBdiffusion5, BB6 - BBdiffusion6

Table 4. Statistical estimates for broadband diffusion regression model

\begin{tabular}{lllllll}
\hline & B & S.E. & Wald & Df & Sig. & Exp(B) \\
\hline BBdiffusion1 & .446 & .234 & 3.628 & 1 & .057 & 1.562 \\
BBdiffusion2 & -.033 & .192 & .029 & 1 & .864 & .968 \\
BBdiffusion3 & .020 & .222 & .008 & 1 & .930 & 1.020 \\
BBdiffusion4 & .035 & .259 & .019 & 1 & .891 & 1.036 \\
BBdiffusion5 & -.531 & .288 & 3.409 & 1 & .065 & .588 \\
BBdiffusion6 & -.121 & .192 & .395 & 1 & .530 & .886 \\
Constant & .488 & .731 & .445 & 1 & .504 & 1.629 \\
\hline
\end{tabular}

After running the logistic regression model, the results obtained were summarized in the table shown below. The table contains the main statistical estimates namely: regression coefficient (B), the Wald statistic (to test the statistical significance) and the all-important Odds Ratio (Exp (B)) for each variable category. The Exp (B) column tells us the number of times the construct factor contributed to innovation effectiveness (INNOVATIVE). For example, BBdiffusion1 contributed the highest number of times to innovation at 1.562 times more than the other factors while the lowest contribution was made by BBdiffusion6 at .886 times. Dependent variable coefficients represented by S.E are statistically significantly different from 0 (zero).

This section provides an explanation of inferential statistics used to evaluate the overall logistic regression model. It also presents goodness-of-fit statistics, statistical tests of individual predictors and validations of predicted probabilities.

Firstly, the Hosmer and Lemeshow Test Chi-square of 8.273 with a p-value of .407 indicated that the model as a whole fitted significantly better than a null model $(\mathrm{p}<0.5)$. Secondly the log likelihood had a value of 196.484. This showed that the model fitted the data.

Thirdly, another descriptive measure of goodness of fit used in the inferential analysis was $R^{2}$. This study utilized the Cox and Snell $R^{2}$ and the Nagelkerke $R^{2}$. Cox and Snell $R^{2}$ had a value of .041 while the Nagelkerke $R^{2}$ had a value of .055 . This is a clear indication that the predictor variables explained only between $4.1 \%$ and $5.5 \%$ of the changes in innovation implementation effectiveness as per the data collected in this study.

Fourthly, to test for inferential goodness-of-fit, this study utilized the Omnibus tests of model coefficient which yielded a chi square of 6.203 and a p-value of 0.023 . The null hypothesis could have stated that the data fits the logistic regression model, with the alternative stating that the data does not fit the logistic regression model. A p-value of 0.407 which formed the basis for rejecting the null hypothesis. It showed that there was evidence for poor goodness of fit of the data. 
DOI: 10.21522/TIJAR.2014.04.02.Art021

ISSN: $2520-3088$

The data collected on the variable constructs for this model showed little capacity to predict innovation since the approach to prediction was correct $59.3 \%$ of the time for the null model and after regression, the model correctly classified the outcome for only $60 \%$ of the cases compared to $59.3 \%$ in the null model. The difference is an improvement of only $0.7 \%$ which was very small!

Table 5. Inferential statistics for broadband diffusion regression model

\begin{tabular}{ll}
\hline Statistic & Value \\
\hline $\begin{array}{l}\text { Hosmer and Lemeshow Test Chi- } \\
\text { square }\end{array}$ & 8.273 Sig. 0.407 \\
p-value & .407 \\
Log likelihood & 196.484 \\
Cox \& Snell R Square & .041 \\
Nagelkerke R Square & .055 \\
Omnibus Tests Chi-square & 6.203
\end{tabular}

This section sort to establish how IHL in Kenya have embraced broadband technology. The study particularly wanted to find out the extent to which broadband had diffused in this institutions. The study seek answers on the impact of broadband speed, cost, number of users, amount of bandwidth available, accessibility and usability. Only $18 \%$ agreed that broadband speed is good, $35.3 \%$ agreed that there were many broadband users in their institutions, $13.3 \%$ agreed that the high cost of bandwidth limits its usability in their institutions, $12 \%$ think the mount of bandwidth available in their institution is adequate, $31.3 \%$ could access the internet from within their institutions and only $9.3 \%$ of the respondents strongly observe that they can use broadband comfortably to perform their academic work in their institutions. Figure 1 below represents these opinion by respondents.

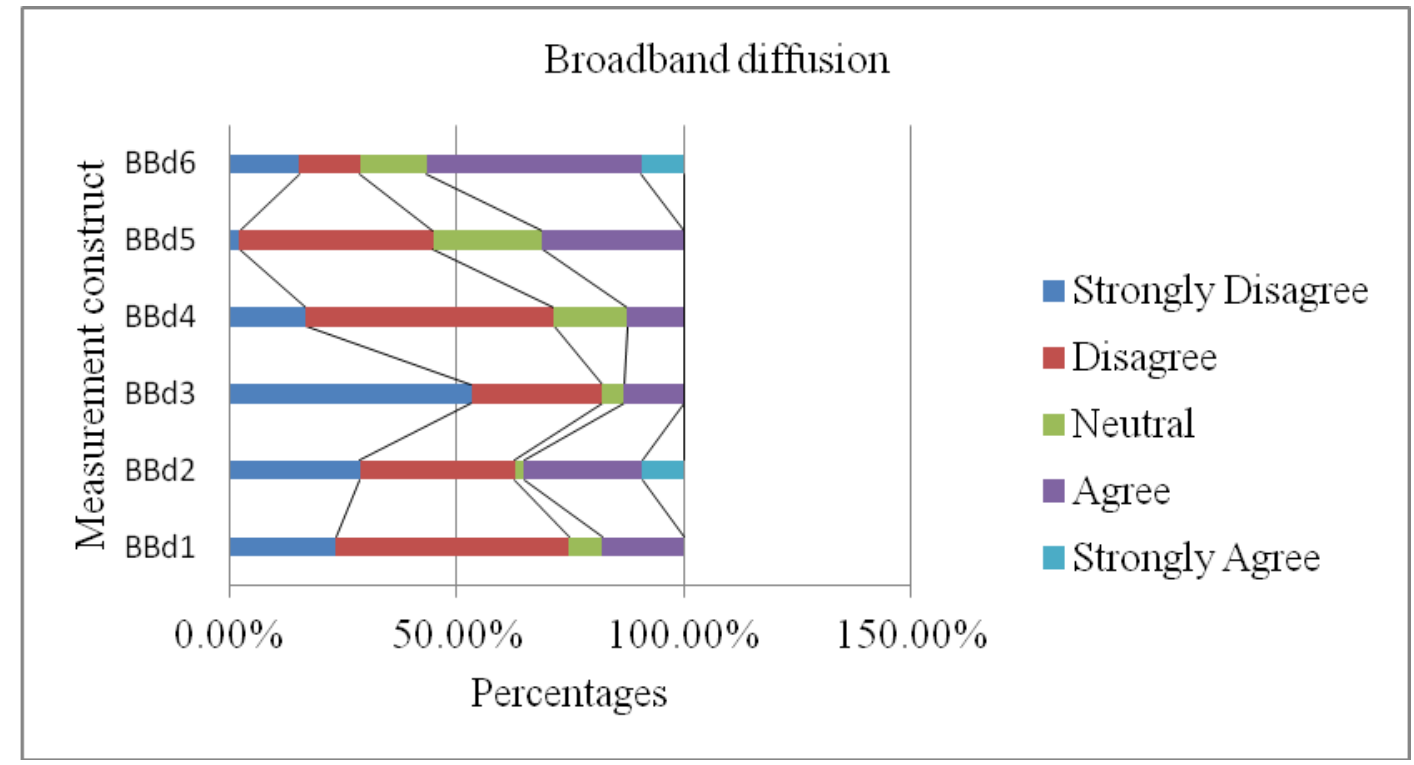

Figure 1. Responses for broadband diffusion 
Table 6. Descriptive statistics for broadband diffusion

\begin{tabular}{lclllll}
\hline & $\mathrm{BBd} 1$ & $\mathrm{BBd} 2$ & $\mathrm{BBd} 3$ & $\mathrm{BBd} 4$ & $\mathrm{BBd} 5$ & $\mathrm{BBd} 6$ \\
\hline $\mathrm{N}$ & 150 & 150 & 150 & 150 & 150 & 150 \\
Mean & 2.2000 & 2.5333 & 1.7800 & 2.2467 & 2.8467 & 3.2200 \\
Std. & .99664 & 1.38383 & 1.03541 & .88186 & .89545 & 1.24712 \\
Deviation & & & & & & .802 \\
Variance & .993 & 1.915 & 1.072 & .778 & 1.555 \\
Minimum & 1.00 & 1.00 & 1.00 & 1.00 & 1.00 & 1.00 \\
Maximum & 4.00 & 5.00 & 4.00 & 4.00 & 4.00 & 5.00 \\
\hline
\end{tabular}

Table 7. Response for broadband diffusion

\begin{tabular}{|c|c|c|c|c|c|c|}
\hline & BBd1 & $\mathrm{BBd} 2$ & $\mathrm{BBd} 3$ & $\mathrm{BBd} 4$ & BBd5 & BBd6 \\
\hline $\begin{array}{l}\text { Strongly } \\
\text { Disagree }\end{array}$ & $23.3 \%$ & $28.7 \%$ & $53.3 \%$ & $16.7 \%$ & $2.0 \%$ & $\%$ \\
\hline Disagree & $51.3 \%$ & $34.0 \%$ & $28.7 \%$ & $54.7 \%$ & $42.7 \%$ & $\%^{13.3}$ \\
\hline Neutral & $7.3 \%$ & $2.0 \%$ & $4.7 \%$ & $16.0 \%$ & $24.0 \%$ & $\%^{14.7}$ \\
\hline Agree & $18.0 \%$ & $26.0 \%$ & $13.3 \%$ & $12.7 \%$ & $31.3 \%$ & $\%^{47.3}$ \\
\hline $\begin{array}{l}\text { Strongly } \\
\text { Agree }\end{array}$ & & $9.3 \%$ & & & & $9.3 \%$ \\
\hline
\end{tabular}

Even after the government of Kenya through the ICT Authority implemented Phase 11 of the National Optic Fibre Broadband Infrastructure (NOFBI), which was complete in June 2016, the cost of broadband still remains high to date. This is despite the fact that it was advertised that the prices with drop tremendously. The price of bandwidth connection in Mbps has improved by a very small margin. For a 5 mbps band and below, the price improved by $17 \%$ from US $\$ 300$ to US $\$ 250$ per unit. In some cases there was no change in the prices. For a 30-49.99 band, the price improved by $17 \%$ from US $\$ 120$ to stand at US $\$ 100$ per unit. The table below shows the price changes for different bandwidth band subscription categories.

Table 8. Price changes for different bandwidth band subscription categories.

\begin{tabular}{llll}
\hline $\begin{array}{l}\text { Bandwidth band } \\
\text { Mbps }\end{array}$ & $\begin{array}{l}\text { Previous Unit } \\
\text { Price \$ Old }\end{array}$ & $\begin{array}{l}\text { New Prices w.e.f July } 2016 \\
\text { Unit Price \$ New }\end{array}$ & $\begin{array}{l}\text { Percentage } \\
\text { Reduction\% }\end{array}$ \\
\hline under 5 & 300 & 250 & $-17 \%$ \\
$5-9.99$ & 250 & 200 & $-20 \%$ \\
$10-14.99$ & 150 & 150 & $0 \%$ \\
$15-29.99$ & 130 & 120 & $-8 \%$ \\
$30-49.99$ & 120 & 100 & $-17 \%$ \\
$50-74$ & 110 & 100 & $-9 \%$ \\
$75-100$ & 100 & 90 & $-10 \%$ \\
$101-150$ & 80 & 80 & $0 \%$ \\
$151-200$ & 80 & 70 & $12.50 \%$ \\
$201-500$ & 60 & 60 & $0 \%$ \\
$501-1250$ & 50 & 50 & $0 \%$ \\
Above 1250 & 50 & 40 & $-25 \%$ \\
\hline
\end{tabular}

Source: Kenet data 
DOI: $10.21522 / \mathrm{TIJAR} .2014 .04 .02 . A r t 021$

ISSN: $2520-3088$

The effect of a change in bandwidth prices has seen an increase in the number of universities purchasing bandwidth from KENET. Some universities have even increased their bandwidth subscriptions. The figure below shows the number of universities that subscribed to different bandwidth band categories in May, 2017.

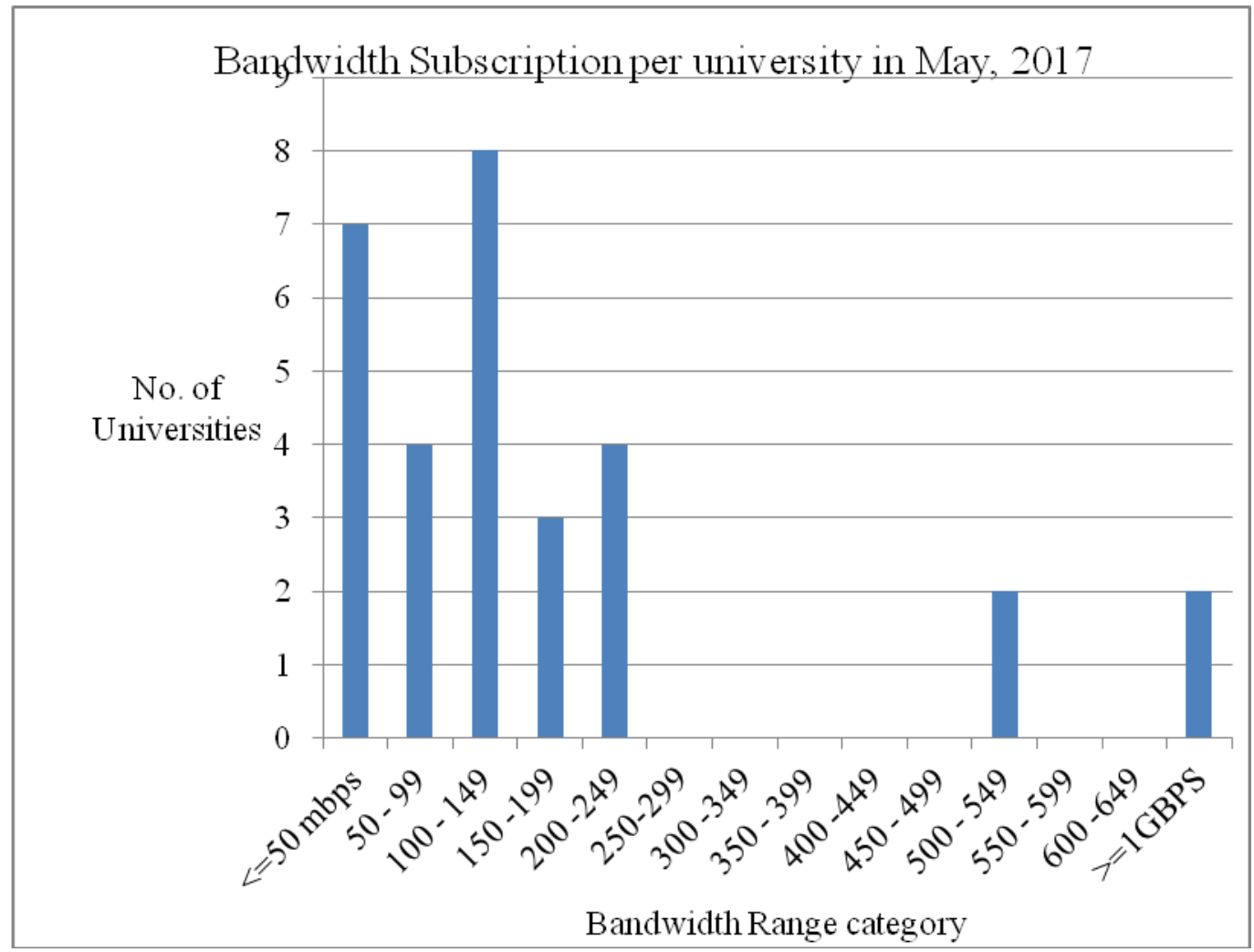

Figure 2. Bandwidth subscription per university

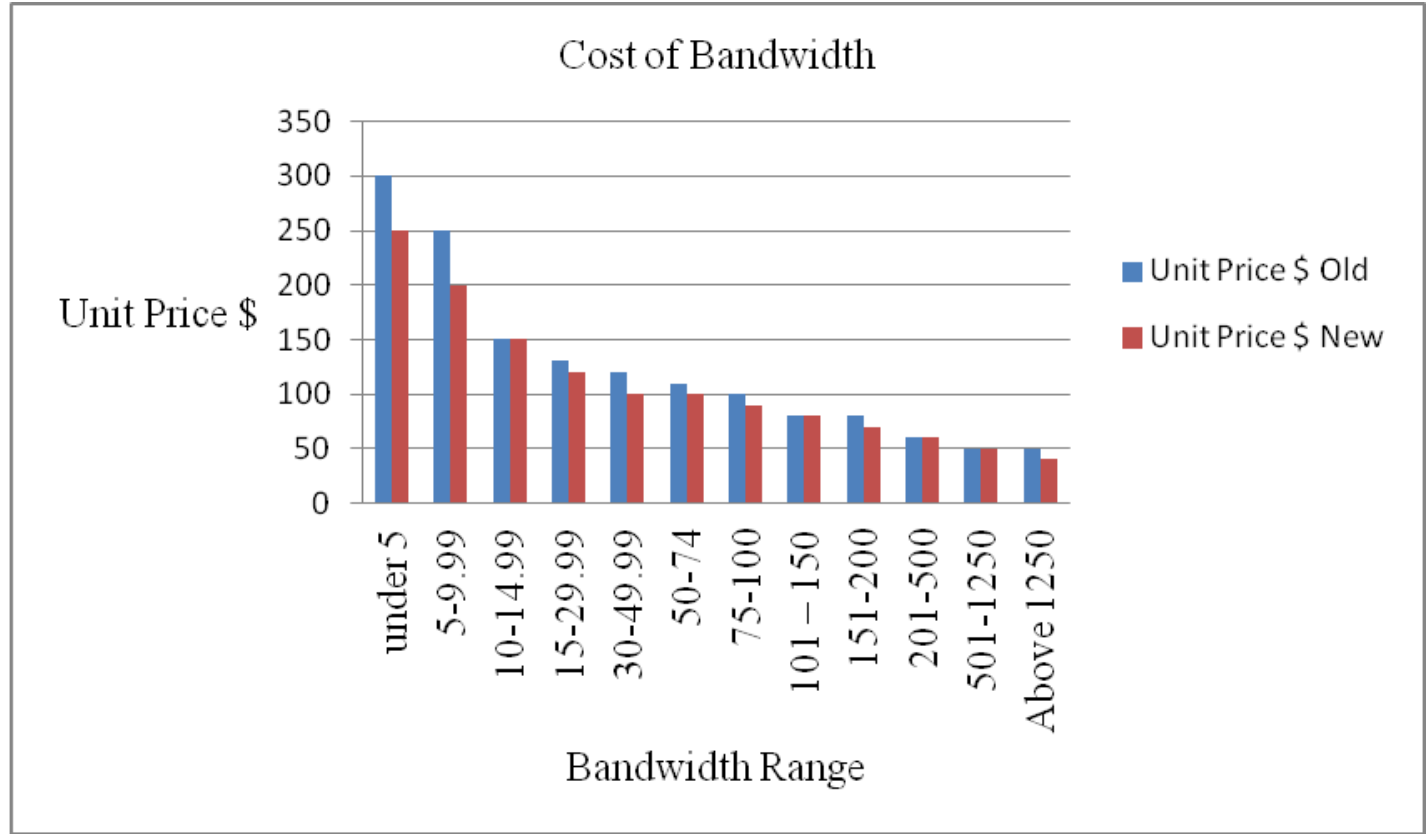

Figure 2. Cost of bandwidth

Broadband speed is a determinant of innovation. Streaming video is rapidly growing as a percentage of internet traffic, requiring increasingly large amounts of bandwidth and raising requirements for timely packet delivery. Advanced internet-based applications such as telemedicine 
deliver many benefits but require low latency and high quality of service. The Internet promises to vastly increase the number of devices communicating via Internet and hence the amount of data transmitted and number of broadband connections. Growth in Cloud-based services create greater demand for bandwidth, especially in combination with Big Data applications that capture and process vast quantities of data derived from everyday activities. The figure below shows online applications requirements for transmission speed.

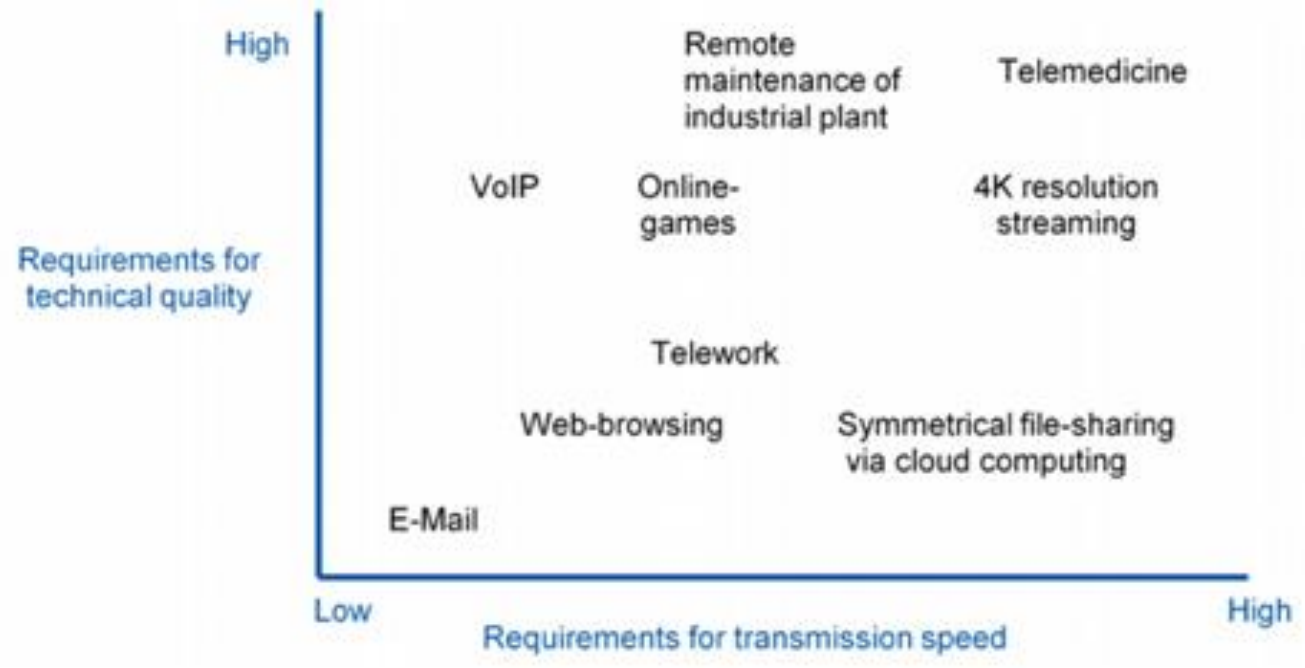

Figure 3. Online applications requirements for transmission speed

Source: Deutsche Bank Research, 2014

The table below shows a comparison of broadband services possible at different speeds

Table 9. Broadband services possible at different transmission Speeds

\begin{tabular}{|l|l|}
\hline Speed range & Possible services that can be supported \\
\hline $\begin{array}{l}\text { Mbps kbps }-1 \\
1 \mathrm{Mbps}-5 \mathrm{Mbps}\end{array}$ & $\begin{array}{l}\text { voice over Internet protocol (VOIP), short message service (SMS), basic } \\
\text { email, web browsing simple sites, streaming music using caching low quality } \\
\text { and highly compressed video }\end{array}$ \\
\hline $\begin{array}{l}\text { Web browsing complex sites, email with larger file attachments, remote } \\
\text { surveillance, internet protocol TV-standard definition (IPTV-SD), small and } \\
\text { medium size file sharing, ordinary telecommuting, one channel of digital } \\
\text { broadcast video, and streaming music }\end{array}$ \\
\hline Mbps & $\begin{array}{l}\text { Advanced telecommunicating, large size file sharing multiple channels of } \\
\text { IPTV-SD, broadcast SD video two to three channels of video streaming high, } \\
\text { definition (HD) video downloading, low definition telepresence, gaming, basic } \\
\text { medical file sharing and remote diagnosis, remote education, and building } \\
\text { control and management }\end{array}$ \\
\hline $\begin{array}{l}100 \mathrm{Mbps}-1 \\
\text { Gbps }\end{array}$ & $\begin{array}{l}\text { HD telemedicine, multiple educational services, full HD broadcast video, full } \\
\text { IPTV channels, video on demand HD, immersion gaming, and telecommuting } \\
\text { with remote server services }\end{array}$ \\
\hline $1 \mathrm{Gbps}-10 \mathrm{Gbps}$ & $\begin{array}{l}\text { Research applications, uncompressed HD video streaming telepresence, live } \\
\text { event digital cinema streaming telemedicine with remote control of medical }\end{array}$ \\
\hline
\end{tabular}


DOI: 10.21522/TIJAR.2014.04.02.Art021

ISSN: $2520-3088$

\begin{tabular}{|l|l|}
\hline & $\begin{array}{l}\text { instruments, interactive remote visualization and virtual reality, sharing } \\
\text { terabyte size datasets, and remote supercomputing }\end{array}$ \\
\hline
\end{tabular}

Source: Broadband deployment as technological innovation: Assessing the needs of Anchor Institutions by Charles C. Hinnant, Charles R. McClure, Lauren H. Mandel (2012)

\section{Discussion}

The objective of the study was to study the role of broadband diffusion in assessing technological innovations. Analysis of the regression model constructed revealed that the data fitted the model well. Firstly, the Hosmer and Lemeshow Test Chi-square indicated that the model as a whole fitted significantly better than a null model. Secondly the log likelihood showed that the model fitted the data.

Thirdly, Cox and Snell $R^{2}$ and the Nagelkerke $R^{2}$ indicated that the predictor variables explained only between $4.1 \%$ and $5.5 \%$ of the changes in innovation implementation effectiveness. Fourthly, to test for inferential goodness-of-fit, this study utilized the Omnibus tests of model coefficient which formed the basis for rejecting the null hypothesis that stated that the data did not fit the logistic regression model.

The data collected on the variable constructs for this model showed little capacity to predict innovation since the approach to prediction improved by only $0.7 \%$ which was very small! This is supported by responses obtained from the research during data collection. The study seek answers on the impact of broadband speed, cost, number of users, amount of bandwidth available, accessibility and usability. Only $18 \%$ agreed that broadband speed is good, $35.3 \%$ agreed that there were many broadband users in their institutions, $13.3 \%$ agreed that the high cost of bandwidth limits its usability in their institutions, $12 \%$ think the mount of bandwidth available in their institution is adequate, $31.3 \%$ could access the internet from within their institutions and only $9.3 \%$ of the respondents strongly observe that they can use broadband comfortably to perform their academic work in their institutions.

\section{Conclusion and recommendation}

Institutions of higher learning in Kenya should ensure that adequate bandwidth is available to staff and students to comfortably perform their activities related to academic work. Connection speed is related to the number of users accessing the internet at the same time. Policy should be put in place to ensure the ratio of users to available bandwidth is acceptable. Access to broadband should not be limited to laboratory or classrooms use but should be available even outside within the institutions. This enables those with laptops and other portable devices access to broadband.

Competition is healthy in any business environment. It encourages adoption of more sophisticated methods of operation and service delivery in order to have a competitive edge from other business rivalries. Universities compete amongst themselves to increase enrolments in order to improve their capital base. They achieve this by increasing the number of programs they offer as well as improve the quality of services they provide. Competition also arises among technologies and among broadband Internet service providers. Technologies competing for BI provision in kenya include; satellite, Digital Subscriber Line ((DSL), cable mode provision and wireless.

Broadband internet service providers operating in Kenya include safaricom, orange Telkom, airtel and essar. Others include Jamii Telecom, liquid Telcom, access Kenya Group, Kenya Education Network (KENET), Wananchi Group, Internet solutions and MTN. Competition brings down the costs of BI, improves BI penetration levels, improves the quality standards of services delivered and improves cooperate governance standards. This has the effect of encouraging foreign investments, better salaries and incentives as well as encourage intellectual property protection laws. 


\section{References}

[1].Anderson, J.C., Gerbing, D.W., 1988. Structural equation modeling in practice: a review and recommended two-step approach. Psychological Bulletin 103, 423-441.

[2].Cava-Ferreruela, I., Alabau- Muňoz, A., 2006. Broadband policy assessment: A cross-national empirical analysis. Telecommunications Policy 30, 445-463.

[3].Chin, W., 1998. Issues and opinion on structural equation modeling. MIS Quarterly 22 (1), 7-16.

[4].Chwelos, P., Benbasat, I., Dexter, A.S., 2001. Research report: empirical test of an EDI adoption model. Information System Research 12 (3), 304-321.

[5].Denni, M., Gruber, H., 2005. The diffusion of broadband telecommunications: The role of competition. Paper presented at International Telecommunication Conference, Pontevedra.

[6].Distaso, W., Lupi, P., Maneti, F.M., 2006. Platform competition and broadband uptake: Theory and empirical evidence from the European Union. Information Economics and Policy 18, 87- 106.

[7].Fronell, C.R., 1982. A Second Generation of Multivariate Analysis Methods. Praeger, New York.

[8].Gandal, N., 2002. Compatibility, Standardization, and network effects: Some policy implications. Oxford Review of Economic Policy 18, 80-91.

[9].Garcia-Murillo, M., 2005. International broadband deployment: The impact of unbundling.

Communications and Strategies 57, 83-108.

[10]. Grosso, M., 2006. Determinants of broadband penetration in OECD nations. Paper presented to the Australian Communications Policy and Research Forum.

[11]. Gruber, H., Verboven F., 2001. The evolution of markets under entry and standards regulation: The case of global mobile telecommunications. International Journal of Industrial Organization 19, 1189-1212.

[12]. Hair, J.F., Anderson, R.E., Tatham, R.L., Black, W.C., 1995. Multivariate Data Analysis with Readings. Prentice-Hall International, Englewood Cliffs.

[13]. ITU, 2003. Promoting broadband: Background paper for workshop on promoting broadband. Electronic document at http://www.itu.int.

[14]. ITU, 2006. Digital.life. ITU, Geneva.

[15]. ITU, 2010. ICT Statistics. ITU, Geneva.

[16]. Kim, J. H., Bauer, J.M., Wildman, S.S., 2003. Broadband uptake in OECD countries: Policy lessons from comparative statistical analysis. Paper presented at the 31st Research Conference on Communication, Information and Internet policy. Arlington, Virginia.

[17]. Koutroumpis, P., 2009. The economic impact of broadband on growth: A simultaneous approach. Telecommunications Policy 33, 471-485.

[18]. Lehr, W., Gillett, S., Osorio, C., Sirbu, M., 2006. Measuring broadband's economic impact. Broadband Properties, 12-24.

[19]. Lohmoller, J.B., 1989. Latent Variable Path Modeling with Partial Least Square Analysis. Physica-Verlag, Heidelberg.

[20]. OECD, 2010. OECD broadband statistics. OECD, Paris.

[21]. Peng, C.-Y. J., Lee, K. L., \& Ingersoll, G. M. (2002). An introduction to logistic regression analysis and reporting. The Journal of Educational Research, 96(1), 3- 14.doi:10.1080/00220670209598786

[22]. Rouvinen, P., 2006. Diffusion of digital mobile telephony: Are developing countries different? Telecommunications Policy 30, 46-63. 